\title{
Consumo e Digestiblidades Aparentes Totais e Parciais de Dietas Contendo Diferentes Níveis de Concentrado, em Novilhos Nelore ${ }^{1}$
}

\section{Márcio Machado Ladeira ${ }^{2}$, Sebastião de Campos Valadares Filho ${ }^{3}$, José Fernando Coelho da Silva $^{3}$, Maria Ignez Leão ${ }^{4}$, Ricardo Linhares Sampaio ${ }^{5}$}

\begin{abstract}
RESUMO - O objetivo deste experimento foi avaliar os efeitos dos níveis de concentrado das dietas sobre os consumos e as digestibilidades aparentes totais e parciais de matéria seca (MS), matéria orgânica (MO), proteína bruta (PB), extrato etéreo (EE), fibra em detergente neutro (FDN) e carboidratos totais (CHO). O efeito das coletas realizadas durante o dia e a noite, para as digestibilidades aparentes totais e parciais da MS e MO, também foi avaliado. Quatro novilhos Nelore, não-castrados, fístulados no rúmen, abomaso e íleo, alimentados à vontade com rações que continham 25,$0 ; 37,5 ; 50,0 ; 62,5 ;$ e 75,0\% de concentrado, foram distribuídos delineamento em blocos casualizados. Foi utilizado o óxido crômico como indicador, na dose de $20 \mathrm{~g} /$ dia. O consumo de MS, MO, NDT e EE aumentou e o de FDN decresceu linearmente com o aumento dos níveis de concentrado nas rações. Houve efeito quadrático para as digestibilidades aparentes totais da MS e MO, em que os valores mínimos foram estimados em 67,27 e 68,31\%, com 36,71 e 41,5\% de concentrado nas rações, respectivamente. As digestibilidades aparentes ruminais da MS e MO foram, em média, 63,35 e 71,42\%, respectivamente. O aumento de concentrado nas rações reduziu a digestão ruminal da FDN. À medida que se reduziu o teor de FDN, ocorreu aumento linear tanto para NDT, quanto para a digestibilidade total da MS. Não houve diferenças para as digestibilidades aparentes totais e parciais da MS e MO obtidas em coletas realizadas durante o dia ou a noite.
\end{abstract}

Palavras-chave: bovinos, concentrado, digestibilidade, consumo

\section{Intake and Total and Partial Apparent Digestibilities of Diets with Different Levels of Concentrate, in Nellore Bulls}

\begin{abstract}
The objective of this experiment was to evaluate the effects of the concentrate level in the diets on the intakes and total and partial apparent digestibilities of dry matter (DM), organic matter (OM), crude protein (CP), ether extract (EE), neutral detergent fiber (NDF) and total carbohydrates (CHO). The effect of collections carried out during the day and the night, for the DM and OM total and partial apparent digestibilities, was also evaluated. Four Nellore bulls, fistulated in the rumen, abomasum and ileum, fed diets ad libitum with $25.0 ; 37.5 ; 50.0 ; 62.5$; and $75.0 \%$ of concentrate, were randomly allotted to a completely randomized block design. The chromium oxide was used as indicator, in the dose of $20 \mathrm{~g} /$ day. The intakes of DM, OM, total digestible nutrients (TDN) and EE increased and that of NDF decreased linearly with the increase of the concentrate in the diets. The minimum estimated total apparent digestibilities of $67.27 \%$ for DM and $68.31 \%$ for OM were with 36.71 and $41.5 \%$ of concentrate in the diets, respectively. The ruminal apparent digestibilities of DM and OM averaged 63.35 and $71.42 \%$, respectively. The increase of concentrate in the diets reduced the ruminal digestion of NDF, but resulted in linear increase in TDN and total DM digestibility of the diets. There were no differences for the total and partial apparent digestibilities of DM and OM obtained in collections accomplished during the day or the night.

Key Words: bulls, concentrate, digestibility, intake

\section{Introdução}

O consumo é um dos pontos importantes que pode limitar o nível de produtividade em bovinos de corte, ou seja, maiores ganhos de peso em intervalo mais curto. O consumo é regulado por vários fatores: animal (peso vivo, nível de produção e estado fisiológico), alimento (fibra, densidade energética, volume,

entre outros) e condições de alimentação (disponibilidade de alimento, freqüência de alimentação, dentre outros), como descrito por MERTENS (1992).

Segundo THIAGO e GILL (1990), há dois fatores que limitam o consumo: quando se fornecem aos animais forragens com baixas taxas de digestão, o fator limitante é a capacidade física do rúmen, por outro lado, quando forragens com altas taxas de
\end{abstract}

\footnotetext{
${ }^{1}$ Parte da Tese apresentada à UFV para obtenção do título "Magister Scientiae". Projeto financiado pelo FINEP/CNPq.

${ }^{2}$ Aluno de Doutorado/Escola de Veterinária/UFMG.

${ }^{3}$ Professor Titular da UFV. Bolsista do CNPq.

${ }^{4}$ Professor Titular da UFV.

5 BolsistaPIBIC/CNPq.
} 
digestão são ingeridas, a liberação de nutrientes no rúmen limitaria o consumo.

Ao trabalhar com 12,$5 ; 25,0 ; 37,5$; e $50 \%$ de concentrado e feno de capim Brachiaria decumbens, RODRIGUEZ (1994) verificou que houve incremento nos consumos de matéria seca (MS) e matéria orgânica (MO), a cada aumento do nível de concentrado, no intervalo de 12,5 a 37,5\%. Já em relação ao consumo de fibra em detergente neutro (FDN), não se constatou diferença, reforçando a hipótese de que a fibra seria fator limitante de consumo.

REYNOLDS et al. (1991), quando submeteram novilhas a dietas com mesmos teores de energia metabolizável, concluíram que as alimentadas com $75 \%$ de concentrado apresentaram menores consumos de MS, energia e proteína, em comparação às que ingeriram $75 \%$ de alfafa.

$\mathrm{O}$ baixo conteúdo de proteína bruta $(\mathrm{PB})$ no alimento também pode ser limitante para o consumo e para a digestibilidade deste, devido à falta de substrato nitrogenado adequado para os microrganismos (FICK et al., 1973). O consumo também está diretamente relacionado à velocidade de esvaziamento do rúmen e à digestibilidade do alimento (BALCH e CAMPLING, 1962).

Dados obtidos por OKAMOTO et al. (1985) demonstraram que não houve diferença para os coeficientes de digestibilidade da MS, PB, fibra bruta (FB), extrato etéreo (EE) e a ingestão de nutrientes digestíveis totais (NDT) em bezerros da raça holandesa PC, alimentados diariamente com 1,2; 1,6; e 2, $0 \mathrm{~kg}$ de concentrado mais feno de capim-rhodes (Chloris gayana). Em relação ao extrato não-nitrogenado, esses autores encontraram diferença para os níveis de concentrado. GONÇALVES (1988), entretanto, revelou aumento para a digestibilidade da matéria seca com variação do nível de concentrado de 20 para $60 \%$ da dieta.

Ao trabalharem com dietas para novilhos contendo diferentes níveis de energia (2,17 e 2,90 Mcal) e FDN (37,95 e 56,30\%), CECAVA et al. (1991) encontraram diferentes digestibilidades aparentes totais da MO, em que os valores médios foram de 73,2 e $84 \%$, para alto e baixo teores de FDN, respectivamente. No entanto, POORE et al. (1990) constataram aumento na digestibilidade total da MS, quando se elevou o nível de concentrado da ração, mas isto não influenciou a digestibilidade da FDN. Urias (1986) e Van Soest (1982), citados pelos mesmos autores, mostraram que a FDN de concentrados é potencialmente mais digestível que a de forrageiras.

Além de se avaliar a digestibilidade total dos alimen- tos, deve-se determinar a digestão parcial dos nutrientes, para se conhecer melhor cada etapa do processo digestivo e fazer avaliação mais detalhada dos alimentos.

Ao trabalharem com feno de capim-gordura (Melinis minutiflora) e níveis de concentrado de 40 e $60 \%$, BATISTA et al. (1983) não encontraram diferença para as digestibilidades ruminais e intestinais da MS, MO e PB. Contudo, ANDRADE (1992), utilizando feno de capim-gordura (Melinis minutiflora) e níveis de 20 e $60 \%$ de concentrado, observou maior digestão ruminal da MS para o menor nível de concentrado, verificando que, do total da MS digestível, 62,3\% foram digeridas no rúmen. Esse autor verificou que a ração com maior nível de concentrado foi mais digerida no intestino delgado e, em média, 7,95\% da MS digestível foram fermentadas no intestino grosso.

Segundo BERCHIELLI (1994), ao se aumentar o nível de concentrado de uma ração, há redução na digestibilidade ruminal, com conseqüente aumento na digestão pós-ruminal da MS, devido à maior taxa de passagem, quando se utilizam dietas com altos níveis de concentrado.

O presente trabalho foi conduzido com o objetivo de se avaliarem em novilhos Nelore o efeito dos níveis de concentrado nas rações, sobre os consumos e as digestibilidades aparentes totais e parciais de MS, MO, $\mathrm{PB}, \mathrm{EE}$, carboidratos totais (CHO), FDN e carboidratos não-estruturais (CNE), e o efeito entre as coletas realizadas durante o dia e a noite, para as digestibilidades aparentes totais e parciais da MS e MO.

\section{Material e Métodos}

O experimento foi conduzido nas dependências do Departamento de Zootecnia (DZO) da Universidade Federal de Viçosa, em Viçosa, MG.

Foram utilizados quatro novilhos Nelore, nãocastrados, com peso vivo médio inicial de $244,6 \mathrm{~kg}$, distribuídos em delineamento de blocos casualizados, sendo cinco níveis de concentrados (tratamentos), quatro animais (blocos) e cinco períodos experimentais.

Os animais foram fistulados no rúmen, abomaso e íleo, segundo as técnicas descritas por LEÃO e COELHO DA SILVA (1980), sendo mantidos no Laboratório de Animais do DZO, em regime de confinamento, em baias individuais, cobertas, com 3 x 3 m de área, providas de comedouro de concreto e bebedouro automático.

Os tratamentos foram constituídos de fenos de capim braquiária (Brachiaria decumbens, Stapf) e coast-cross (Cynodon dactylon), em proporções 
iguais, e concentrado (fubá de milho, farelo de soja, uréia e minerais), cujos níveis nas rações foram, em porcentagem, de 25,$0 ; 37,5 ; 50,0 ; 62,5$; e 75,0. As rações foram balanceadas de acordo com o Cornell Net Carbohydrate and Protein System (CNCPS), citado por BARRY et al. (1994).

As proporções dos ingredientes nos concentrados estão na Tabela 1. A composição química dos concentrados e fenos encontra-se na Tabela 2 e a composição das rações, na Tabela 3 .

Os cinco períodos tiveram duração de 14 dias cada, sendo utilizados 10 dias para adaptação e quatro dias para coletas de fezes e digesta de abomaso e íleo. Os animais foram pesados no início e final de cada período experimental. Para determinar o consumo, foram realizadas, diariamente, as pesagens e amostragens dos alimentos e das sobras. A quantidade de ração fornecida diariamente foi calculada para permitir sobras de aproximadamente $10 \%$. Do feno fornecido, foram feitas amostras compostas por período; do concentrado, por tratamento; e das sobras por animal em cada período. As amostras foram armazenadas a $-5^{\circ} \mathrm{C}$ para posteriores análises.

Para determinação das digestibilidades, foi utilizado o óxido crômico como indicador externo, que foi introduzido diretamente na fístula ruminal em duas doses diárias de $10 \mathrm{~g}$ cada, durante os últimos sete dias do período de adaptação e nos quatro dias de coletas, às $8 \mathrm{~h} 30 \mathrm{e} 16 \mathrm{~h} 30$. As coletas de fezes, abomaso e íleo foram efetuadas a intervalos de oito horas, com intervalo de seis horas entre dias, de forma que no final de quatro dias fossem obtidas 12 amostras de fezes e digestas de abomaso e íleo, por animal, conforme metodologia descrita por CALSAMIGLIA et al. (1995). O esquema foi o seguinte: dia 1 , coletas às 8,16 e $24 \mathrm{~h}$; dia 2 , coletas às 6,14 e $22 \mathrm{~h}$; dia 3 , coletas às 4,12 e $20 \mathrm{~h}$; e dia 4 , coletas às 2,10 e $18 \mathrm{~h}$.

As amostras de fezes, abomaso e íleo foram guardadas em congelador, sendo ao final de cada período experimental pré-secas em estufa a $65^{\circ} \mathrm{C}$ e moídas. Uma amostra composta foi elaborada para o período do dia (6-16 h) e da noite (18-4 h), por animal, com base no peso seco.

Os teores de MS, MO, compostos nitrogenados totais $(\mathrm{N}), \mathrm{EE}, \mathrm{FDN}$ e cromo foram determinados conforme técnica descrita por SILVA (1990), enquanto a $\mathrm{PB}=\mathrm{N} \times 6,25$.

Os CHO foram calculados de acordo com SNIFFEN et al. (1992): $100-(\% \mathrm{~PB}+\% \mathrm{EE}+\%$ Cinzas). De acordo com esses autores, foram obtidos os teores de carboidratos não-estruturais (CNE) pela
Tabela 1 - Proporção do ingrediente usado no concentrado (\%MN)

Table 1 - Ingredient proportion used in the concentrate (\% as fed) Ingrediente Concentrado

Ingredient Concentrate

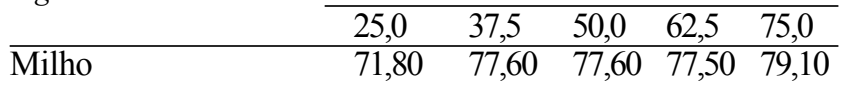

Corn

$\begin{array}{llllll}\text { Farelo de soja } & 20,00 & 20,00 & 20,20 & 20,00 & 18,30\end{array}$

Soybean meal

$\begin{array}{llllll}\text { Uréia } & 0,88 & 1,18 & 1,22 & 1,25 & 1,26\end{array}$

Urea

Fosfato bicálcico $\quad 0,26 \quad 0,26 \quad 0,26 \quad 0,26 \quad 0,26$

Dicalcium phosphate

Calcário

Limestone

Sal comum

Salt

$\begin{array}{llllll}\text { Sulfato de cobalto }^{1} \quad 0,20 & 0,12 & 0,10 & 0,10 & 0,10\end{array}$

Cobalt sulfate

Sulfato de cobre ${ }^{1}$

Copper sulfate

$\begin{array}{llllll}\text { Iodato de potássio }^{1} \quad 0,40 & 0,24 & 0,18 & 0,14 & 0,12\end{array}$

Potassium iodate

$\begin{array}{llllll}\text { Sulfato de zinco }^{1} & 46,00 & 31,00 & 23,00 & 18,50 & 16,00\end{array}$

Zinc sulfate

${ }^{1} \mathrm{~g} / 100 \mathrm{~kg}$.

diferença entre $\mathrm{CHO}$ e FDN.

Os teores de NDT e energia metabolizável das rações foram calculados segundo SNIFFEN et al.(1992).

Os dados de consumo e digestibilidade foram avaliados por meio de análises de variância e regressão, utilizando-se o programa SAEG (Sistema de Análises Estatísticas e Gerenciais).

O modelo estatístico empregado foi:

em que

$$
Y_{i j}=m+t_{i}+b_{j}+e_{i j}
$$

$\mathrm{Y}_{\mathrm{ij}}=$ valor observado na parcela relativa ao tratamento i no bloco $\mathrm{j}$;

$\mathrm{m}=$ média geral;

$\mathrm{t}_{\mathrm{i}}=$ efeito do tratamento $\mathrm{i}$

$b_{j}=$ efeito do bloco $j$;

$\mathrm{e}_{\mathrm{ij}}=$ efeito dos fatores não-controlados;

$\mathrm{i}=25,0 ; 37,5 ; 50,0 ; 62,5 ;$ e $75 \%$ de concentrado na ração; e

$\mathrm{j}=$ animais utilizados no experimento.

\section{Resultados e Discussão}

Os resultados referentes aos consumos médios de MS, MO, FDN, NDT, CHO, CNE, EE e PB, bem como as equações de regressão e os coeficientes de variação e determinação, são encontrados na 
LADEIRA et al.

Tabela 2 - Teor de matéria seca (MS), matéria orgânica (MO), proteína bruta (PB), fibra em detergente neutro (FDN), extrato etéreo (EE), carboidratos totais $(\mathrm{CHO})$ e carboidratos não-estruturais (CNE) dos concentrados e fenos

Table 2 - Content of dry matter (DM), organic matter (OM), crude protein (CP), neutral detergent fiber (NDF), ether extract (EE), total carbohydrates (CHO) and non-structural carbohydrates (NSC) of the concentrate and hays

\begin{tabular}{|c|c|c|c|c|c|c|c|}
\hline \multirow[b]{2}{*}{ Item } & \multicolumn{5}{|c|}{$\begin{array}{l}\text { Concentrado } \\
\text { Concentrate }\end{array}$} & \multicolumn{2}{|c|}{$\begin{array}{r}\text { Feno } \\
\text { Hay }\end{array}$} \\
\hline & 25,0 & 37,5 & 50,0 & 62,5 & 75,0 & Braquiária & Coast-cross \\
\hline MS\% & 84,87 & 85,79 & 86,62 & 87,31 & 87,11 & 87,03 & 86,73 \\
\hline$D M$ & & & & & & & \\
\hline $\mathrm{MO}^{1}$ & 96,58 & 97,07 & 97,13 & 97,16 & 96,84 & 94,37 & 93,88 \\
\hline $\begin{array}{l}O M \\
\mathrm{~PB}^{1} \\
C P\end{array}$ & 17,93 & 18,57 & 18,89 & 18,90 & 19,18 & 3,58 & 8,84 \\
\hline $\begin{array}{l}\mathrm{FDN}^{1} \\
N D F\end{array}$ & 14,84 & 13,41 & 15,44 & 16,54 & 15,74 & 79,82 & 83,19 \\
\hline $\mathrm{EE}^{1}$ & 2,11 & 1,17 & 1,49 & 2,33 & 2,80 & 0,90 & 0,82 \\
\hline $\mathrm{CHO}^{1}$ & 76,54 & 77,33 & 76,75 & 75,93 & 74,86 & 89,89 & 84,22 \\
\hline $\begin{array}{l}\mathrm{CNE}^{1} \\
N S C\end{array}$ & 61,70 & 63,92 & 61,31 & 59,39 & 59,12 & 10,07 & 1,03 \\
\hline
\end{tabular}

${ }_{1}$ Porcentagem da MS (DM percentage).

Tabela 3 - Teor médio de matéria seca (MS), matéria orgânica (MO), proteína bruta (PB), fibra em detergente neutro (FDN), extrato etéreo (EE), carboidratos totais ( $\mathrm{CHO})$, carboidratos nãoestruturais (CNE), nutriente digestível total (NDT) e concentração de energia metabolizável (EM) nas rações

Table 3 - Average content of dry matter (DM), organic matter (OM), crude protein (CP), neutral detergent fiber (NDF), ether extract (EE), total carbohydrates (CHO), nonstructural carbohydrate (NSC), total digestible nutrient $(T D N)$ and metabolizable energy concentration in the diets

\begin{tabular}{|c|c|c|c|c|c|}
\hline \multirow[t]{2}{*}{ Item } & \multicolumn{5}{|c|}{$\begin{array}{l}\text { Nível de concentrado } \\
\text { Concentrate level }\end{array}$} \\
\hline & 25,0 & 37,5 & 50,0 & 62,5 & 75,0 \\
\hline $\mathrm{MS} \%$ & 86,38 & 86,47 & 86,75 & 87,15 & 87,05 \\
\hline$D M$ & & & & & \\
\hline $\mathrm{MO}^{1}$ & 94,69 & 95,19 & 95,60 & 96,00 & 96,15 \\
\hline$O M$ & & & & & \\
\hline $\mathrm{PB}^{1}$ & 8,89 & 10,63 & 12,38 & 14,01 & 15,85 \\
\hline$C P$ & & & & & \\
\hline $\mathrm{FDN}^{1}$ & 64,84 & 55,97 & 48,47 & 40,90 & 32,18 \\
\hline$N D F$ & & & & & \\
\hline $\mathrm{EE}^{1}$ & 1,17 & 0,98 & 1,18 & 1,78 & 2,32 \\
\hline $\mathrm{CHO}^{1}$ & 84,63 & 83,58 & 82,04 & 80,21 & 77,98 \\
\hline $\mathrm{CNE}$ & 19,80 & 27,61 & 33,57 & 39,31 & 45,80 \\
\hline$N S C$ & & & & & \\
\hline $\mathrm{NDT}^{1}$ & 67,00 & 66,49 & 69,14 & 73,52 & 77,20 \\
\hline$T D N$ & & & & & \\
\hline $\mathrm{EM}^{2}$ & 2,42 & 2,40 & 2,50 & 2,65 & 2,79 \\
\hline$M E$ & & & & & \\
\hline
\end{tabular}

\footnotetext{
1 Porcentagem da MS (DM percentage).
}

Tabela 4. Houve aumento linear no consumo de MS, independente de ser expresso em $\mathrm{kg} / \mathrm{dia}$, \% PV ou $\mathrm{g} / \mathrm{kg}^{0,75}$. Este aumento no consumo de MS, em função do aumento nos níveis de concentrado nas rações, pode ter ocorrido em virtude da menor quantidade de FDN ingerida, quando os animais receberam dietas com altos níveis de concentrado. Assim, podese predizer que o consumo foi limitado, quando os animais foram submetidos a dietas com mais baixo teores de concentrado, devido ao enchimento do rúmen, em decorrência dos aumentos nos níveis de fibra. Estes dados refletem os resultados obtidos por ANDRADE (1992) e RODRIGUEZ (1994), mas são diferentes dos de CARVALHO (1996), que não encontrou efeito do aumento dos níveis de concentrado nas rações sobre o consumo de MS.

Os consumos de MO e NDT aumentaram linearmente, à medida que se elevaram os níveis de concentrado na ração, enquanto o de FDN apresentou decréscimo linear, independente de ser expresso em $\mathrm{kg} / \mathrm{dia}, \% \mathrm{PV}$ ou g/ $\mathrm{kg}^{0,75}$. No tratamento com $25 \%$ de concentrado, o consumo de FDN, em porcentagem de peso vivo, foi de $1,12 \%$, valor este muito próximo do valor ótimo sugerido, para vacas em lactação, por MERTENS (1992), que é de 1,20\%. No tratamento com $75 \%$, o consumo de FDN foi de 1,64 kg, o que, 
segundo o NRC (1996), está aquém da necessidade do animal, que é de 1,94 kg. Mesmo considerando o alto teor de concentrado na ração, não se verificou distúrbio metabólico nos animais.

Os consumos de $\mathrm{CHO}, \mathrm{CNE}, \mathrm{EE}$ e $\mathrm{PB}$ tiveram efeito linear positivo em função dos níveis de concentrado na dieta, o que pode ser explicado pelo maior consumo de MS, quando os animais receberam rações com maiores quantidades de concentrado. Além disso, as rações que continham mais concentrado também apresentaram maiores teores de PB, EE e CNE (Tabela 3).

Os dados referentes à comparação entre as digestibilidades aparentes totais e parciais da MS e MO nos períodos de dia (6-16 h) e noite (18-4 h) são encontrados na Tabela 5. Observa-se que não houve diferença nas digestibilidades aparentes calculadas em função das amostras obtidas nos períodos diurno e noturno. Em decorrência disso, as amostras que eram separadas por dia e noite foram misturadas, resultando assim em amostra composta por animal e tratamento, para as demais análises. De acordo com estes resultados, pode-se inferir que somente a realização de coletas durante o dia seria suficiente para se obterem amostras representativas das fezes e digestas de abomaso e íleo.
Os coeficientes de digestibilidades aparentes totais e parciais da MS e MO estão na Tabela 6. Houve efeito quadrático para as digestibilidades aparentes totais da MS e MO, em que os valores mínimos foram estimados em 67,27 e 68,31\%, com 36,71 e 41,5\% de concentrado nas rações, respectivamente.

Mesmo apresentando efeito quadrático com ponto de mínimo, as digestibilidades aparentes encontradas tiveram valores altos, em relação ao consumo de ração (NRC, 1996). TIBO et al. (1997) também encontraram efeito quadrático em novilhos Simental x Nelore alimentados com os mesmos níveis de concentrado. Já RODRIGUEZ (1994) encontrou efeito linear para os coeficientes de digestibilidade aparente da MS em função dos níveis de concentrado.

Não houve efeito dos níveis de concentrado para as digestibilidades ruminais da MS e MO, observando-se valores médios de 63,35 e 71,42\%, respectivamente. BATISTA etal.(1983), BERCHIELLI(1994), DUTRA (1996), CARVALHO (1996) e TIBO et al. (1997) também não encontraram efeito dos níveis de concentrado sobre a digestão ruminal da MS. Em relação à digestão ruminal da MO, ANDRADE(1992), ao submeter novilhos a dietas que continham $20 \mathrm{e}$ $60 \%$ de concentrado, verificou que a taxa de digestão

Tabela 4 -Média e regressão do consumo de matéria seca (MS), matéria orgânica (MO), fibra em detergente neutro (FDN), nutriente digestível total (NDT), carboidrato total (CHO), carboidrato não-estrutural (CNE), extrato etéreo (EE) e proteína bruta (PB), em relação aos níveis de concentrado na dieta

Table 4 - Mean and regression of the intake of dry matter (DM), organic matter (OM), neutral detergent fiber (NDF), total digestible nutrient $(T D N)$, total carbohydrate (CHO), non-structural carbohydrate(NSC), ether extract (EE) and crude protein (CP), on the concentrate levels the diet

\begin{tabular}{|c|c|c|c|c|c|c|c|c|}
\hline \multirow[t]{2}{*}{ Item } & \multicolumn{5}{|c|}{$\begin{array}{l}\text { Nível de concentrado } \\
\text { Concentratelevel }\end{array}$} & \multirow[t]{2}{*}{$\begin{array}{l}\text { Regressão } \\
\text { Regression }\end{array}$} & \multirow[t]{2}{*}{$\mathrm{r}^{2}$} & \multirow[t]{2}{*}{$\mathrm{CV} \%$} \\
\hline & 25,0 & 37,5 & 50 & 62,5 & 75 & & & \\
\hline \multicolumn{9}{|c|}{--------kg/dia $(\mathrm{kg} /$ day)------- } \\
\hline $\mathrm{MS}(D M)$ & 4,80 & 4,18 & 5,16 & 5,85 & 5,26 & $\hat{\mathrm{Y}}=4,025+0,021 * * \mathrm{X}$ & 0,438 & 14,21 \\
\hline $\mathrm{MO}(O M)$ & 4,58 & 3,97 & 4,97 & 5,62 & 5,06 & $\hat{\mathrm{Y}}=3,791+0,021 * * \mathrm{X}$ & 0,460 & 14,36 \\
\hline $\mathrm{FDN}(N D F)$ & 2,94 & 2,14 & 2,27 & 2,29 & 1,64 & $\hat{\mathrm{Y}}=3,239-0,020 * * \mathrm{X}$ & 0,696 & 19,41 \\
\hline $\operatorname{NDT}(T D N)$ & 3,65 & 3,43 & 4,25 & 5,24 & 4,80 & $\hat{\mathrm{Y}}=2,632+0,033^{* *} \mathrm{X}$ & 0,729 & 11,34 \\
\hline \multicolumn{9}{|c|}{--------\%PV $(\% L W)-$} \\
\hline $\mathrm{MS}(D M)$ & 1,83 & 1,68 & 2,08 & 2,31 & 2,05 & $\hat{\mathrm{Y}}=1,566+0,008 * * \mathrm{X}$ & 0,478 & 13,41 \\
\hline $\mathrm{FDN}(N D F)$ & 1,12 & 0,87 & 0,91 & 0,90 & 0,64 & $\hat{\mathrm{Y}}=1,262-0,007 * * \mathrm{X}$ & 0,734 & 18,33 \\
\hline $\operatorname{NDT}(T D N)$ & $1,1,39$ & 1,36 & 1,72 & 2,08 & 1,90 & $\hat{\mathrm{Y}}=1,001+0,014 * * \mathrm{X}$ & 0,762 & 10,38 \\
\hline $\mathrm{MS}(D M)$ & 73,75 & 66,65 & 82,39 & 92,04 & 81,80 & $\hat{\mathrm{Y}}=62,73+0,332 * * \mathrm{X}$ & 0,467 & 14,12 \\
\hline $\mathrm{FDN}(N D F)$ & 45,16 & 34,34 & 36,28 & 35,99 & 25,51 & $\hat{\hat{Y}}=50,52-0,301 * * X$ & 0,726 & 13,23 \\
\hline $\operatorname{NDT}(T D N)$ & 56,07 & 54,14 & 68,06 & 82,63 & 75,50 & $\hat{\mathrm{Y}}=40,34+0,539 * * \mathrm{X}$ & 0,753 & 10,20 \\
\hline \multicolumn{9}{|c|}{--------kg/dia (kg/day)------- } \\
\hline $\mathrm{CHO}$ & 3,72 & 3,26 & 4,25 & 5,05 & 4,30 & $\hat{\mathrm{Y}}=0,040+0,019 * * \mathrm{X}$ & 0,410 & 13,74 \\
\hline CNE (NSC) & 0,78 & 1,10 & 1,98 & 2,75 & 2,66 & $\hat{\mathrm{Y}}=0,806+0,039 * * \mathrm{X}$ & 0,902 & 17,32 \\
\hline $\mathrm{EE}$ & 0,06 & 0,05 & 0,07 & 0,12 & 0,14 & $\hat{\mathrm{Y}}=-0,004+0,002 * * \mathrm{X}$ & 0,810 & 15,57 \\
\hline $\mathrm{PB}(C P)$ & 0,48 & 0,54 & 0,71 & 0,87 & 0,82 & $\hat{\mathrm{Y}}=0,276+0,008 * * \mathrm{X}$ & 0,879 & 22,65 \\
\hline
\end{tabular}

** Significativo $(\mathrm{P}<0,01)$, pelo teste t.

** Significant $(P<.01)$ by $t$ test. 
Tabela 5 -Média da digestibilidade aparente da matéria seca e materia orgânica total (DAMS e DAMO), no rúmen (DRMS e DRMO), no intestino delgado (DIDMS e DIDMO) e no intestino grosso (DIGMS e DIGMO), no período do dia ou da noite

Table 5 - Mean of the total apparent digestibility of dry matter and organic matter ( $A D D M$ and $A D O M$ ), in the rumen (RDDM and $R D O M$ ), in the small intestine (SIDDM and SIDOM) and in the large intestine (LIDDM and LIDOM), in the period of day or night

\begin{tabular}{lccc}
\hline & \multicolumn{2}{c}{ Metodologia (Methodology) } & \\
\cline { 2 - 3 } Item & Dia(Day) & Noite (Night) & CV\% \\
\hline DAMS (ADDM) & $63,84 \mathrm{a}$ & $65,69 \mathrm{a}$ & 12,60 \\
DAMO (ADOM) & $66,16 \mathrm{a}$ & $67,89 \mathrm{a}$ & 11,32 \\
DRMS (RDDM) & $49,19 \mathrm{a}$ & $52,46 \mathrm{a}$ & 19,79 \\
DRMO (RDOM) & $60,67 \mathrm{a}$ & $61,51 \mathrm{a}$ & 17,30 \\
DIDMS (SIDDM) & $31,27 \mathrm{a}$ & $27,92 \mathrm{a}$ & 31,59 \\
DIDMO (SIDOM) & $24,39 \mathrm{a}$ & $22,56 \mathrm{a}$ & 41,49 \\
DIGMS (LIDDM) & $19,55 \mathrm{a}$ & $19,62 \mathrm{a}$ & 31,20 \\
DIGMO (LIDOM) & $15,94 \mathrm{a}$ & $14,93 \mathrm{a}$ & 43,40 \\
\hline Médias, na linha, seguidas por letras diferentes são diferentes \\
\multicolumn{3}{l}{ (P<0,05) pelo teste F. } \\
\multicolumn{3}{l}{ Means, within a row, followed by different letters are different (P<.05) by $F$ test. }
\end{tabular}

nos animais, cuja dieta era constituída de $20 \%$ de concentrado, foi de $67,49 \%$, portanto, mais elevada que a taxa de digestão de $60,02 \%$ dos animais alimentados com $60 \%$ de concentrado. CECAVA et al. (1991) encontraram maior quantidade de matéria orgânica fermentada no rúmen, nos animais alimentados com rações que continham maiores níveis de concentrado; contudo, DUTRA (1996) não verificou diferença na digestão ruminal da $\mathrm{MO}$, em função do teor de FDN nas rações.

As digestibilidades aparentes da MS e MO no intestino delgado aumentaram linearmente com os níveis de concentrado, o que pode ser explicado pela maior quantidade de CNE presente nas rações com maiores níveis de concentrado. Contudo, DUTRA (1996) e CARVALHO (1996) não encontraram efeito dos níveis de concentrado nas digestibilidades intestinais da MS e MO.

As digestibilidades aparentes da MS e MO no intestino grosso apresentaram decréscimo linear, ou seja, o contrário do que ocorreu no ID, devido, possivelmente, à maior quantidade de carboidratos estruturais presentes nas rações com menores níveis de concentrado.

As relações entre NDT e FDN e a digestibilidade total da matéria seca (DIGTMS) e FDN foram avaliadas por intermédio de equações de regressão, sendo obtidas as seguintes equações: NDT $=87,108$ $-0,339$ FDN $\left(r^{2}=0,88 ; \mathrm{P}<0,01\right)$ e DIGTMS $=84,404$ - 0,284 FDN ( $\left.\mathrm{r}^{2}=0,72 ; \mathrm{P}<0,05\right)$. Estas equações mostraram que, à medida que se reduziu o teor de FDN, ocorreu aumento linear, tanto para NDT quan- to para a DIGTMS, e também possibilitaram a estimativa do valor energético das rações, a partir do conhecimento do teor de FDN das mesmas.

Os coeficientes de digestibilidade aparente total e parcial da PB e EE são encontrados na Tabela 7. Houve aumento linear para a digestibilidade aparente total da $\mathrm{PB}$ e efeito quadrático para a do EE, em que a digestibilidade mínima de $58,20 \%$ foi estimada para nível de $32,7 \%$ de concentrado. Estes dados diferem dos de alguns autores, que não observaram efeito dos níveis de concentrados sobre as digestibilidades aparentes da PB (ANDRADE, 1992; RODRIGUEZ, 1994; e CARVALHO, 1996) e do EE (OKAMOTO et al., 1985 e CARVALHO, 1996).

A digestibilidade de $\mathrm{PB}$ no rúmen apresentou efeito linear, em que, para os maiores níveis de concentrado, as perdas de proteína no rúmen foram maiores. Segundo CARVALHO (1996), isto significa que houve absorção de amônia no rúmen. Os resultados negativos para os tratamentos com 25 e $37,5 \%$ de concentrado podem significar pequena deficiência dietética de proteína degradável no rúmen (PDR).

As perdas ruminais de proteína ocorridas nos animais que receberam rações com 50,$0 ; 62,5$; e $75,0 \%$ de concentrado podem ser oriundas do excesso de PDR na ração. Vale ressaltar que as rações não foram isoprotéicas (Tabela 3).

Foi encontrado efeito quadrático para a digestibilidade aparente ruminal do EE. Os valores negativos para a digestão do EE podem ser conseqüência da síntese de lipídeos microbianos.

No intestino delgado (ID) foram encontrados aumentos lineares nos coeficientes de digestibilidade da PB e do EE. LIMA (1986) também verificou maior digestão de PB no ID para bovinos alimentados com rações que continham $60 \%$ de concentrado, todavia, BATISTA et al. (1983) e CARVALHO (1996) não observaram diferenças entre níveis de concentrado. Os valores encontrados para $\mathrm{PB}$ estão próximos aos $65 \%$ para nitrogênio não-amoniacal e $68 \%$ para aminoácidos apresentados pelo NRC (1985) e também aos 70\% para a proteína apresentados pelo ARC (1984). Os valores observados para o EE são menores que o valor de $95 \%$ sugerido por SNIFFEN et al. (1992).

No intestino grosso houve decréscimo linear nos coeficientes de digestibilidade da $\mathrm{PB}$, em função dos níveis de concentrado, o que difere do observado por CARVALHO (1996), que não encontrou efeito.

Não houve efeito dos níveis de concentrado $(\mathrm{P}>0,05)$ sobre os coeficientes de digestibilidade do EE no intestino grosso, em que a média foi de 15,10\%. 
Rev. bras. zootec.

Tabela 6 - Média e regressão da digestibilidade aparente total e ruminal, no intestino delgado e no intestino grosso, da matéria seca (MS) e matéria orgânica (MO), em relação aos níveis de concentrado na dieta

Table 6 - Mean and regression of the total and ruminal apparent digestibility, in the small intestine and in the large intestine, of the dry matter $(D M)$ and organic matter (OM), on the concentrate level in the diet

\begin{tabular}{|c|c|c|c|c|c|c|c|c|}
\hline \multirow[t]{2}{*}{ Item } & \multicolumn{5}{|c|}{$\begin{array}{c}\text { Nível de concentrado } \\
\text { Concentratelevel }\end{array}$} & \multirow[t]{2}{*}{$\begin{array}{l}\text { Regressão } \\
\text { Regression }\end{array}$} & \multirow[t]{2}{*}{$\mathrm{r}^{2}$} & \multirow[t]{2}{*}{$\mathrm{CV} \%$} \\
\hline & 25,0 & 37,5 & 50 & 62,5 & 75 & & & \\
\hline \multicolumn{9}{|c|}{ Digestibilidade total (Total digestibilty) } \\
\hline $\operatorname{MS}(D M)$ & 68,69 & 66,00 & 69,19 & 72,05 & 77,18 & $\hat{\mathrm{Y}}=76,702-0,514 * \mathrm{X}+0,007 * \mathrm{X}^{2}$ & 0,966 & 7,14 \\
\hline $\mathrm{MO}(O M)$ & 70,64 & 68,34 & 70,93 & 72,24 & 78,68 & $\hat{\hat{Y}}=80,37-0,581 * X+0,007 * * X^{2}$ & 0,963 & 6,38 \\
\hline \multicolumn{9}{|c|}{ Digestibilidade ruminal (Ruminal digestibility) ${ }^{1}$} \\
\hline $\operatorname{MS}(D M)$ & 67,10 & 63,42 & 58,09 & 66,44 & 61,70 & $\hat{\mathrm{Y}}=63,35$ & & 15,11 \\
\hline $\mathrm{MO}(O M)$ & 75,71 & 71,50 & 69,15 & 74,51 & 66,21 & $\hat{\mathrm{Y}}=71,42$ & & 14,75 \\
\hline \multicolumn{9}{|c|}{ Digestibilidade no intestino delgado (Digestibility in the small intestine) ${ }^{1}$} \\
\hline $\operatorname{MS}(D M)$ & 15,55 & 22,75 & 25,46 & 24,02 & 25,47 & $\hat{\mathrm{Y}}=14,200+0,169^{*} \mathrm{X}$ & 65,44 & 39,70 \\
\hline $\mathrm{MO}(O M)$ & 10,52 & 17,14 & 19,18 & 18,43 & 24,00 & $\hat{\mathrm{Y}}=6,560+0,226 * * \mathrm{X}$ & 0,847 & 54,91 \\
\hline \multicolumn{9}{|c|}{ Digestibilidade no intestino grosso (Digestibility in the large intestine) ${ }^{1}$} \\
\hline $\operatorname{MS}(D M)$ & 19,26 & 13,84 & 16,45 & 9,53 & 12,83 & $\hat{\mathrm{Y}}=21,252-0,137 * * \mathrm{X}$ & 54,31 & 36,06 \\
\hline $\mathrm{MO}(O M)$ & 15,24 & 11,35 & 11,67 & 7,07 & 9,79 & $\hat{\mathrm{Y}}=17,101-0,122 * * \mathrm{X}$ & 0,650 & 41,36 \\
\hline
\end{tabular}

${ }^{*} \mathrm{e}^{* *}$ Significativo $(\mathrm{P}<0,05 \mathrm{e}<0,01)$, respectivamente, pelo teste $\mathrm{t}$.

$X=$ Nível de concentrado na dieta.

${ }^{1}$ Digestibilidades calculadas em função do total digestível.

${ }^{*}$ and ${ }^{* *}$ Significant at $(P<.05$ e $<.01)$, respectively, for the $t$ test.

$X=$ Concentrate level in the diet.

${ }^{1}$ Digestibilities calculated in function of total digestible.

Tabela 7 - Média e regressão da digestibilidade aparente total e ruminal, no intestino delgado e no intestino grosso, da proteína bruta $(\mathrm{PB})$ e do extrato etéreo (EE), em relação aos níveis de concentrado na dieta

Table 7- Mean and regression of the total and ruminal apparent digestibility, in the small intestine and in the large intestine, of the crude protein $(C P)$ and ether extratct (EE), on the concentrate levels in the diet

\begin{tabular}{|c|c|c|c|c|c|c|c|c|}
\hline \multirow[t]{2}{*}{ Item } & \multicolumn{5}{|c|}{$\begin{array}{l}\text { Nível de concentrado } \\
\text { Concentratelevel }\end{array}$} & \multirow[t]{2}{*}{$\begin{array}{l}\text { Regressão } \\
\text { Regression }\end{array}$} & \multirow[t]{2}{*}{$\mathrm{r}^{2}$} & \multirow[t]{2}{*}{$\mathrm{CV} \%$} \\
\hline & 25,0 & 37,5 & 50 & 62,5 & 75 & & & \\
\hline & \multicolumn{8}{|c|}{ Digestibilidade total (Total digestibilty) } \\
\hline $\mathrm{PB}(C P)$ & 67,27 & 70,00 & 71,45 & 75,16 & 78,62 & $\hat{\mathrm{Y}}=61,354+0,223$ & 0,980 & 7,43 \\
\hline \multirow[t]{2}{*}{$\mathrm{EE}$} & 62,25 & 50,85 & 62,70 & 75,85 & 79,89 & $\hat{Y}=74,223-0,981 * X+0,015^{*} X^{2}$ & 0,802 & 15,35 \\
\hline & \multicolumn{8}{|c|}{ Digestibilidade ruminal (Ruminal digestibility) ${ }^{1}$} \\
\hline $\mathrm{PB}(C P)$ & $-3,88$ & $-0,65$ & 3,30 & 14,01 & 8,25 & $\hat{Y}=-11,359+0,311 * X$ & 0,749 & 419,70 \\
\hline \multirow[t]{2}{*}{$\mathrm{EE}$} & $-54,23$ & $-122,57$ & $-94,54$ & $-20,36$ & $-11,18$ & $\hat{\mathrm{Y}}=64,371-7,658 * \mathrm{X}+0,092 * * \mathrm{X}^{2}$ & 0,709 & 39,04 \\
\hline & \multicolumn{8}{|c|}{ Digestibilidade no intestino delgado (Digestibility in the small intestine) ${ }^{1}$} \\
\hline $\mathrm{PB}(C P)$ & 56,67 & 64,78 & 64,32 & 66,84 & 69,96 & $\hat{\mathrm{Y}}=53,058+0,229 * * \mathrm{X}$ & 0,848 & 11,99 \\
\hline \multirow[t]{2}{*}{$\mathrm{EE}$} & 68,12 & 74,30 & 74,82 & 77,60 & 79,80 & $\hat{\mathrm{Y}}=64,258+0,213 * * \mathrm{X}$ & 0,916 & 6,57 \\
\hline & \multicolumn{8}{|c|}{ Digestibilidade no intestino grosso (Digestibility in the large intestine) ${ }^{1}$} \\
\hline $\mathrm{PB}(C P)$ & 24,80 & 14,26 & 13,65 & 10,74 & 10,86 & $\hat{\mathrm{Y}}=27,416-0,251^{*} \mathrm{X}$ & 0,738 & 92,42 \\
\hline L & 23,16 & 13,43 & 18,83 & 10,54 & 9,56 & $\hat{\mathrm{Y}}=15,10$ & & 134,74 \\
\hline
\end{tabular}

${ }^{*} \mathrm{e}{ }^{* *}$ Significativo a $\mathrm{P}<0,05$ e $\mathrm{P}<0,01$, respectivamente, pelo teste $\mathrm{t}$.

$X=$ Nível de concentrado na dieta.

1 Digestibilidades calculadas em função da quantidade que chegou em cada compartimento.

* and ** Significant at $P<.05$ e $P<.01$, respectively, for the $t$ test.

$X=$ Concentrate level in the diet.

${ }^{1}$ Digestibilities calculated in function of the amount that arrived in each compartiment. 
Tabela 8 - Média e regressão da digestibilidade aparente total e ruminal, no intestino delgado e intestino grosso, da fibra em detergente neutro (FDN) e dos carboidratos totais (CHO), em relação aos níveis de concentrado na dieta

Table 8 - Mean and regression of for the total and ruminal apparent digestibility, in the small intestine and in the large intestine, of the neutral detergent fiber (NDF) total carbohydrates (CHO), on the concentrate levels in the diet

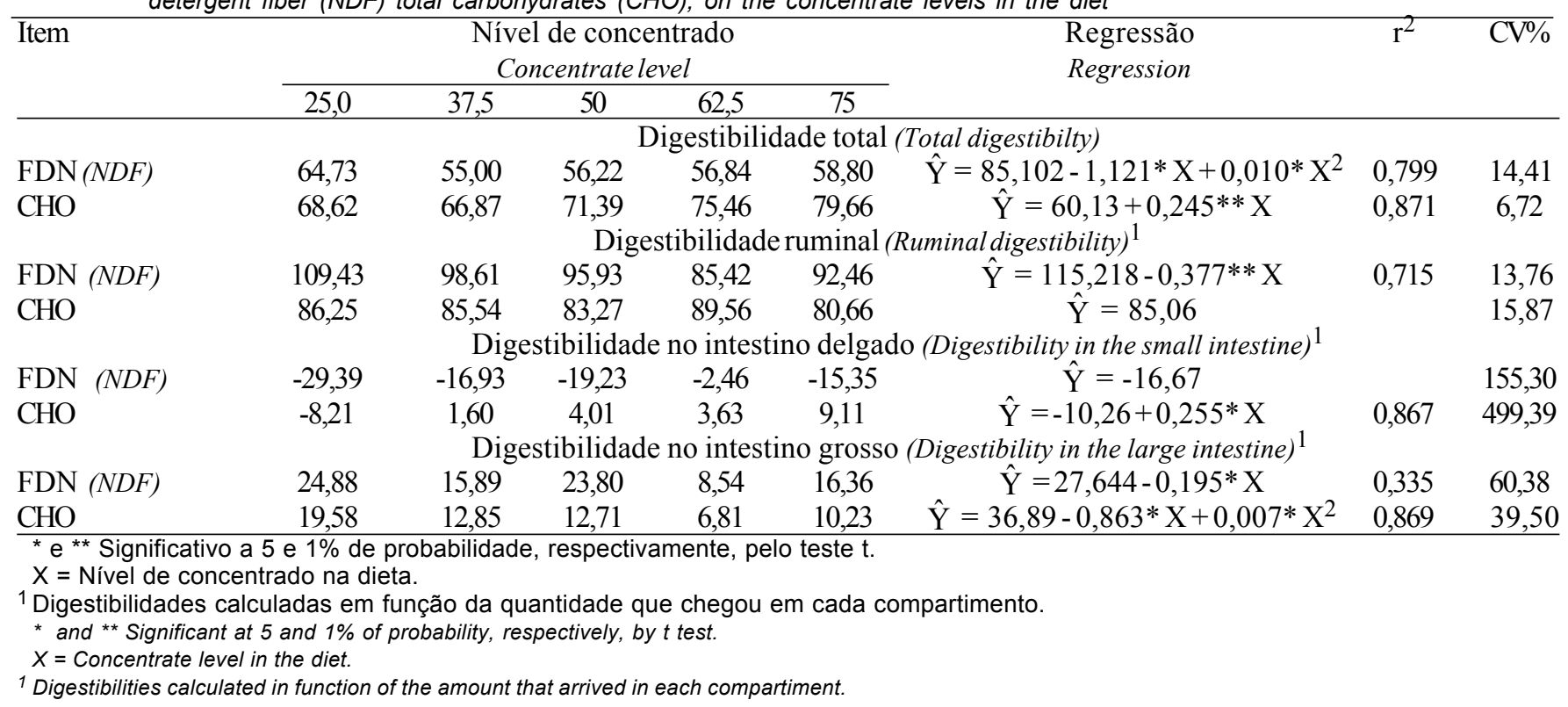

Os coeficientes de digestibilidades aparentes totais e parciais de FDN e CHO estão contidos na Tabela 8. Foi encontrado efeito quadrático para a digestibilidade aparente total da FDN em relação aos níveis de concentrado, em que a digestibilidade mínima estimada foi de $53,69 \%$ para nível de $56,05 \%$ de concentrado. Redução na digestibilidade da FDN deveria ocorrer com o aumento dos níveis de concentrado, em virtude, provavelmente, da menor digestão ruminal. Para os $\mathrm{CHO}$, houve aumento linear, à medida que se aumentou o nível de concentrado nas rações.

A digestibilidade ruminal da FDN apresentou decréscimo linear, com o aumento dos níveis de concentrado, o que pode ser explicado pelo fato de a utilização de níveis elevados de concentrado reduzir $\mathrm{o} \mathrm{pH}$ e, conseqüentemente, a digestão ruminal da FDN. A digestão ruminal dos $\mathrm{CHO}$ não sofreu efeito em relação aos níveis de concentrado, sendo que a média foi de $85,06 \%$. Possivelmente, a redução na digestão ruminal da FDN foi compensada pelo aumento na digestão dos CNE nesse compartimento gástrico.

No intestino delgado a digestibilidade da FDN não foi influenciada pelos níveis de concentrado, enquanto os $\mathrm{CHO}$ foram mais digeridos, devido à maior quantidade de CNE, à medida que se aumentaram os níveis de concentrado.

Em média, a digestibilidade da FDN no intestino delgado foi de $-16,67 \%$, podendo indicar algum erro na estimativa dos fluxos da matéria seca, pois seria esperado valor próximo de zero.

No intestino grosso, a digestibilidade aparente da FDN decresceu linearmente, o que sugere mudança na população microbiana. Para os carboidratos totais foi encontrado efeito quadrático, em que a digestibilidade mínima estimada foi de $10,30 \%$ para o nível de $61,64 \%$ de concentrado na ração; comportamento similar ao encontrado por CARVALHO (1996).

\section{Conclusões}

Os consumos de MS, MO e NDT aumentaram e o de FDN decresceu linearmente com o aumento dos níveis de concentrado nas rações.

As digestibilidades aparentes totais de MS e MO mínimas de 67,27 e $68,31 \%$ foram estimadas com 36,71 e $41,5 \%$ de concentrado nas rações, respectivamente.

As digestibilidades aparentes da MS e MO no rúmen, não foram influenciadas nos diferentes níveis de concentrado, em que as médias foram $63,35 \mathrm{e}$ $71,42 \%$, respectivamente.

$\mathrm{O}$ aumento de concentrado nas rações reduziu a digestão ruminal da FDN.

Não houve diferenças para as digestibilidades aparentes totais e parciais da MS e MO obtidas em coletas realizadas durante o dia e a noite. Dessa forma, pode-se inferir que somente a realização de coletas durante o dia seria suficiente para se obterem amostras representativas das fezes e digestas. 


\section{Referências Bibliogáficas}

AGRICULTURAL RESEARCH COUNCIL - ARC. 1984. The nutrient requeriments of ruminant livestock, Supplement $n$. 1. Report of the Protein Group of the ARC Working Party. London: $\mathrm{CAB}, 45 \mathrm{p}$.

ANDRADE, A. T. Digestão total e parcial da matéria seca, matéria orgânica, energia bruta e proteina em diferentes grupos genéticos de bovídeos. Viçosa, MG, 1992. 181p. Tese (Doutorado em Zootecnia) - Universidade Federal de Viçosa, 1992.

BALCH, C. C., CAMPLING, R. C. 1962. Regulation of voluntary intake in ruminants. Nutrition Abstracts and Reviews, 32(3):669-686.

BARRY, M. C., FOX, D. C., TYLUTKY, T. P. et al. 1994. A manual for using the Cornell Net Carbohydrate and Protein System for evaluating cattle diets. Revised for CNCPS release, 3.ed. Ithaca: Cornell University, 40p.

BATISTA, A. M. V., SILVA, J. F. C., GARACIA, J. A. et al. 1983. Digestões total e parcial em novilhos alimentados com rações contendo soja tratada com formaldeído e duas proporções volumoso:concentrado. R. Soc. Bras. Zootec., 12(4):667-681.

BERCHIELLI, T.T. Efeito da relação volumoso:concentrado sobre a partição da digestão, a sintese de proteina microbiana, produção de ácidos graxos voláteis e o desempenho de novilhos em confinamento. Belo Horizonte, MG, 1994. 104 p. Tese (Doutorado em Zootecnia) - Universidade Federal de Minas Gerais, 1994.

CALSAMIGLiA S., CAJA, G., STERN, M. D. et al. 1995. Effects of ruminal versus duodenal dosing of fish meal on ruminal fermentation and milk composition. J. Dairy Sci., 78(9):1999-2007.

CARVALHO, A. U. Niveis de concentrado na dieta de zebuinos: consumo, digestibilidade e eficiencia microbiana. Viçosa, MG, 1996. 113 p. Tese (Doutorado em Zootecnia) - Universidade Federal de Viçosa, 1996.

CECAVA, M. J., MERCHEN, N. R., GAY, L. C. et al. 1991. Composition of ruminal bacteria harvested from steers as influenced by dietary energy level, feeding frequency and isolation techniques. J. Dairy Sci., 73(9):2480-2488.

DUTRA, A. R. Efeito dos niveis de fibra e de fontes de proteinas sobre a digestão dos nutrientes e sintese de compostos nitrogenados microbianos em novilhos. Viçosa, MG, 1996. 118 p. Dissertação (Mestrado em Zootecnia) - Universidade Federal de Viçosa, 1996.

FICK, K. R., AMMERMAN, C. B., McGOWAN, C. H. et al. 1973. Influence of supplemental energy and biuret nitrogen on the utilization of low quality roughage by sheep. J. Anim. Sci., 36(1):137-143.

GONÇALVES, L.C.Digestibilidade, composição corporal, exigências nutricionais e característica das carcaças de zebuínos, taurinos e bubalinos. Viçosa, MG. 238 p. 1988. Tese (Doutorado em Zootecnia) - Universidade Federal de Viçosa, 1988.

LEÃO, M. I., COELHO DA SILVA, J. F. Técnica de fistulação de abomaso em bezerros. In: REUNIÃO ANUAL DA SOCIEDADE BRASILEIRA DE ZOOTECNIA, 17, 1980, Fortaleza, CE. Anais... Fortaleza: SBZ, p. 37, 1980.

LIMA, F. C. Digestão total e parcial de energia e proteína em taurinos, zebuínos, seus mestiços e em bubalinos. Viçosa, MG, 1986. 120 p. Tese (Doutorado em Zootecnia) - Universidade Federal de Viçosa, 1986.
MERTENS, D. R. Análise da fibra e sua utilização na avaliação e formulação de rações. In: SIMPÓSIO INTERNACIONAL DE RUMINANTES, Lavras, 1992. Anais... Lavras: R.A.S.B.Z., p. 188-219, 1992.

NATIONAL RESEARCH COUNCIL - NRC. 1985. Ruminant nitrogen. Washington, DC.: National Academy Press, 138 p.

NATIONAL RESEARCH COUNCIL - NRC. 1996. Nutrient requeriment of beef cattle. 7 ed., Washington, DC.: National Academy Press, 242 p.

OKAMOTO, F., ANDRADE, P., ROSA, L.C. et al. 1985. Efeitos do grau de moagem do feno e nível de concentrado na digestibilidade aparente de rações para bezerros. $R$. Soc. Bras. Zootec., 14(1):33-38.

POORE, M. H., MOORE, J. A., SWINGLE, R. S. 1990. Differential passage rates and digestion of neutral detergent fiber from grain and forages in 30,60, and 90\% concentrate diets fed to steers. J. Anim. Sci, 68:2965-2973.

REYNOLDS, C. K., TYRRELL, H. F., REYNOLDS, P. J. 1991. Effects of diet forage concentrate ratio and intake on energy metabolism in growing beef heifers: whole body energy and nitrogen balance and visceral heat production. J. Nut., Md: American Institute of Nutrition. 121(7):994-1003.

RODRIGUEZ, L. R. R. Consumo alimentar, digestibilidade, balanço de nitrogênio e excreção de minerais em bovinos (taurinos e zebuinos)e bubalinos. Viçosa, MG, 1994. 69 p. Dissertação (Mestrado em Zootecnia) - Universidade Federal de Viçosa, 1994.

SILVA, D. J. 1990. Análise de alimentos (Métodos químicos e biológicos). Viçosa, MG, UFV, Impr. Univ., 165 p.

SNIFFEN, C. J., O'CONNOR, J. D., VAN SOEST, P. J. et al. 1992. A Net Carbohydrate and Protein System for evaluation cattle diets. II. Carbohydrate and protein availability. $J$. Anim. Sci., 70(11):3562-3577.

THIAGO, L. R. L., GILL, S. 1990. Consumo voluntário: fatores relacionados com a degradação e passagem da forragem pelo rúmen. EMBRAPA - CNPGC, Campo Grande MS, GSP.

TIBO, G. C., VALADARES FILHO, S. C., COELHO da SILVA, J. F. et al. Consumo, digestibilidades e metodologias de coleta de amostras de digesta em novilhos alimentados com vários níveis de concentrado. In: REUNIÃO ANUAL DA SOCIEDADE BRASILEIRA DE ZOOTECNIA, 34, Juiz de Fora, MG, 1997. Anais... Viçosa: SBZ. p. 188-219, 1997.
Recebido em: 08/05/98 Aceito em: 19/09/98 